\title{
Birds respond similarly to taxidermic models and live cuckoos Cuculus canorus
}

\author{
Piotr Tryjanowski $^{1}$ (1) $\cdot$ Federico Morelli ${ }^{2} \cdot$ Zbigniew Kwieciński $^{3} \cdot$ Piotr Indykiewicz $^{4} \cdot$ Anders Pape Møller $^{5}$
}

Received: 5 March 2018 / Accepted: 28 June 2018 / Published online: 7 July 2018

(c) The Author(s) 2018

\begin{abstract}
Stuffed birds are widely used in research for identifying effects of predators and nest parasites on bird behaviour, studying levels of aggression and the size of territories. However, the fact that these models do not move or vocalize may question the results of such studies and open them to criticism. One solution would be to determine how the results of research using stuffed dummies correlate with the response of wild animals to enemies under the same environmental conditions. In a first attempt, we examined the correlation between the intensity of mobbing of a dummy cuckoo Cuculus canorus and interactions with live cuckoos in the field during the breeding season in western Poland. A total of 39 bird species mobbed cuckoo dummies; all 39 were found to attack live cuckoos, while 24 species (61.5\%) did so during experiments using a dummy. The number of individual birds involved in mobbing a dummy was positively correlated with the number of individuals attacking real cuckoos in the same areas, even when the most commonly mobbing species, the barn swallow Hirundo rustica, was excluded from the analyses. However, we did not find significant differences in frequency of mobbing behaviour depending on cuckoo behaviour described as flight or sitting, or calling rather than remaining quiet. Therefore, we conclude that the use of a dummy for studying mobbing of hosts and non-hosts of the cuckoo provide results that are similar to those made in response to the behaviour of live hosts.
\end{abstract}

Keywords Anti-parasite behaviour · Cuckoo $\cdot$ Cuculus canorus $\cdot$ Mobbing

Piotr Tryjanowski

piotr.tryjanowski@gmail.com

1 Institute of Zoology, Poznań University of Life Sciences, Wojska Polskiego 71 C, 60-625 Poznań, Poland

2 Department of Applied Geoinformatics and Spatial Planning, Faculty of Environmental Sciences, Czech University of Life Sciences Prague, Kamýcká 129, 16500 Prague 6, Czech Republic

3 Department of Avian Biology and Ecology, Faculty of Biology, Adam Mickiewicz University, Umultowska 89, 61-614 Poznań, Poland

4 Department of Biology and Animal Environment, University of Technology and Life Sciences, Ks. A. Kordeckiego 20, 85-225 Bydgoszcz, Poland

5 Ecologie Systématique Evolution, Université Paris-Sud, CNRS, AgroParisTech, Université Paris-Saclay, 91405 Orsay Cedex, France

\section{Introduction}

Dummies and stuffed birds are widely used in the study of mobbing of predators (Curio et al. 1978; Suzuki and Ueda 2013; Syrová et al. 2016) and brood parasites, including the common cuckoo Cuculus canorus (Moksnes et al. 1991; Røskaft et al. 2002; Grim 2005). Use of this method produced large amounts of valuable information on predator detectability (Syrová et al. 2016), brood parasite detectability (Mclean 1987; Dyrcz and Hałupka 2006), cognitive ability (Beránková et al. 2014) and many other kinds of behaviour connected with territory size and borders (Curio et al. 1978; Knight and Temple 1986). This method has been commonly used since early studies in quantitative ethology (Altmann 1956; Melzack et al. 1959; Curio et al. 1978). The method is assumed to function well in studies of brood parasitism and allow discrimination between cuckoos and predators, like the sparrowhawk Accipiter nisus and kestrel Falco tinnunculus (Trnka et al. 2012; Gluckman and Mundy 2013), and even allow discrimination between particular 
raptor species (e.g. Soard and Ritchison 2009, Courter and Ritchison 2010).

Although dummies are often used, this method is only useful if validated in the field. However, it has often been confirmed that the method works and that birds attack cuckoo dummies. However, the only test that validates the use of dummies and the response to live cuckoos in the field was reported by Liang and Møller (2015). In situations when there are no explicit tests of whether the presentation of dummies reflects the situation in the field, criticism against the reliability of the use of dummies can be raised and interpretations should be made with caution. First, it is an artificial situation to make tests using a dummy, which mainly remains immobile and silent, as revealed by birds reacting more strongly to flying objects (Schleidt et al. 2011). Birds can discriminate between live and artificial objects and subsequently modulate behaviour (Scriba and Goymann 2008). Moreover, birds may mob an enemy in particular situations as, for example, when flying or sitting and defending a territory (Curio et al. 1978; Syrová et al. 2016). For example, cuckoos may change behaviour while searching for nests of hosts, when vocalizing and when interacting with conspecifics (Teuschl et al. 1998; Møller et al. 2016; Yu et al. 2016; Moskát et al. 2017). Sometimes the reaction of birds to dummies is used to distinguish between the relative importance of particular species such as nest predators or brood parasites, and classically a pigeon is used as a control (reviewed by Grim 2005). However, another way of avoiding criticism is to use as a control dummy an object similar to the tested animal, for example a cuckoo that may influence the results of an experiment leading to erroneous conclusions (Grim 2005). These reflections raise the question of whether experiments with dummies resemble the real situation with live birds in the field.

To address this question, we investigated whether the reaction of birds to a cuckoo dummy in playback experiments reflected the situation for live vocalizing cuckoo males in the field. Here we correlated mobbing against a brood parasite and a dummy, both in experiments and during field observations of live cuckoos. We predicted that if the use of a dummy was reliable in a particular study of the response of a given bird species to a brood parasite, we should find a strong positive correlation between level of aggression in response to a dummy and in the field to live cuckoos. Additionally, we analyzed how bird species reacted to the behaviour of cuckoos (flying vs sitting and calling vs being silent). Such differences in behaviour may provide information relevant for the design of experiments that may better simulate field conditions.

\section{Materials and methods}

\section{Study area}

The field study was conducted during late April-late June 2016 in Wielkopolska province, western Poland $\left(52^{\circ} \mathrm{N}\right.$, $\left.16^{\circ} \mathrm{E}\right)$. Information on the density of cuckoos and potential hosts is reported in Tryjanowski and Morelli (2015). Data were collected in two ways: (1) experimentally using a cuckoo dummy shown together with playback; and (2) by observation of the reaction of birds to live cuckoos recorded in the field.

\section{Dummy experiments}

We simulated natural conditions of cuckoo males in the field by using stuffed cuckoo males (four different individuals from museums). A stuffed cuckoo was provided on a $2.5-\mathrm{m}$ wooden pole. The pole with a stuffed cuckoo was visible, because it was provided at the edge of shrubs, tree clumps, on the bank of small water bodies or on a fence at the edge of a village. The cuckoo was not searching for potential nests of the host species. The dummy was accompanied by a loudspeaker (placed on the slat under the dummy) for playing back cuckoo calls (5 and 50 cu-coo syllables), reflecting the real situation in the field (Møller et al. 2016) to test the importance of call duration, female presence, and time of the breeding season (Tryjanowski, Møller, and Morelli in prep.). To avoid problems with pseudoreplication and potential preferences for the call of a particular male (e.g. Jung et al. 2014), we used synthetic calls of cuckoos prepared with Avisoft SASLab Pro 5.2 (Specht 2016). The synthetic calls were prepared based on their natural equivalent in the following steps: (1) creation of a sonogram, (2) scanning of frequency contour and amplitude envelope, and (3) saving a WAV file. For scanning we used automatic three-threshold element separation and appropriate threshold relative to the maximum signal amplitude. Synthetic calls were very similar acoustically, visually and when compared with calls produced by live cuckoos.

Synthetic calls were pasted into WAV files prepared for broadcasting during experiments. Broadcast sounds began with $60 \mathrm{~s}$ of silence, which allowed the observer to set up the loudspeaker and recede to a standard distance of $100 \mathrm{~m}$ from the loudspeaker before start of playback. After $60 \mathrm{~s}$ the loudspeaker reproduced synthetic calls of two variants: short duration ( 5 cuckoo calls during $6 \mathrm{~s}$ plus $54 \mathrm{~s}$ silence) repeated 5 times, and long duration ( 25 cuckoo calls during $35 \mathrm{~s}$ plus $25 \mathrm{~s}$ of silence), repeated 5 times. Calls were broadcast with a waterproof Creative MUVO mini ${ }^{\circledR}$ loudspeaker and amplitude was standardized for all playbacks. 
Experimental data with dummy and playback were collected during 1 May-15 June 2016 in the morning (6:00-9:30) on days with no rain or strong wind.

\section{Field observations}

Simultaneously with the experiments with playback and in the neighboring area (radius $10 \mathrm{~km}$ ) during follow-up of the experiments, but also on other days, when PT, PI and ZK were searching for additional sites for potential experiments, the same observers recorded responses of birds to live cuckoos. This part of the field work was conducted during 29 April-30 June 2016. This approach allowed collection of data used for analyzing the correlation between data obtained from field observations and playback experiments.

Similar to the method described by Liang and Møller (2015), observed cuckoos were classified as flying or sitting, but observers also paid special attention to whether the cuckoo was calling or silent. Although data were collected at a large spatial scale, we cannot be sure that observations always represented different individuals, just as in other studies of unbanded cuckoos (Welbergen and Davies 2008, 2009; Trnka and Grim 2013; Moskát et al. 2017) and, moreover, more detailed study using radio-transmitters suggested local fidelity (Vogl et al. 2004). Therefore, only the first attack in a particular area (defined as a circle with a radius of $1 \mathrm{~km}$ ) was included in the analyses to avoid pseudoreplication, excluding situations when more cuckoos were observed simultaneously).

PT, ZK and PI quantified the abundance of the local breeding bird community by recorded birds at 184 points at a distance of $100 \mathrm{~m}$ from each calling cuckoo and each dummy presentation. Birds were counted using the pointcount method with 5-minute observations without repetition (Blondel et al. 1970), and then used to describe the breeding bird community in the study area.

\section{Statistical analysis}

In order to avoid errors when recording interactions between cuckoos and other species of birds (nervous behaviour, changes in song pattern) the response of birds to the model cuckoo was included only if the birds physically attacked the dummy cuckoo (mobbing). Similarly, during field observations of live cuckoos only mobbing reactions directed towards the cuckoo were used for analyses. We paid special attention when cuckoos were attacked by other birds, and due to the situation in the field we divided all situations into four categories of cuckoo behaviour: (1) sitting and no calling; (2) flying and no calling; (3) sitting and calling; and (4) flying and calling. Only species recorded at least once (in playback experiments mobbing or during observations of interactions with live cuckoos) were included in the analyses. Hosts of cuckoos were ranked according to the frequency of parasitism of different species in Poland (Wesołowski and Mokwa 2013), the only available data for Poland, but it is worth noting that the use of particular bird species is dynamic and changed temporally in accordance with the arms race hypothesis (Lovászi and Moskát 2004).

We used generalized linear models (GLM) to investigate the association between number of individuals involved in mobbing the dummy and number of individuals observed in the same area mobbing live cuckoos. Models were performed using the 'Ime4' package for R (Bates et al. 2014). The number of individuals mobbing the dummy was modelled as a response variable, assuming a Poisson distribution for this count variable. The covariates were number of individuals attacking live cuckoos, abundance of each species of bird and the interaction between the two variables. The incorporation of abundance of birds in the model can remove any problem related to the possibility of detecting a high rate of attacks just for density-dependent reasons (for instance if abundant species are expected to be found more often attacking both live and dummy cuckoos).

The standardized estimates were obtained using the 'QuantPsyc' package for R (Fletcher 2015). All statistical tests were performed with R software (R Development Core Team 2017).

\section{Results}

In total, among cuckoo mobbers, 39 bird species and 181 individuals were recorded during the study (Table 1). All species were recorded during observations in the field interacting with live cuckoos, and 24 of them $(61.5 \%)$ attacked the dummy during experiments. A total of 89 and 92 individual birds were recorded during observations and playback experiments, respectively. In total in the field the cuckoo was observed in 315 cases, and in 89 cases $(27.6 \%)$ it was mobbed by other species. However, the frequency of mobbing was not significantly related to four types of cuckoo behaviour: (1) sitting and no calling; (2) flying and no calling; (3) sitting and calling; and (4) flying and calling (Pearson chi-square $=1.63, d f=1,3, P=0.202$ ).

There was a significant positive correlation between the number of individuals per species involved in mobbing in experiments with the dummy and observed in the same area attacking live cuckoos (Fig. 1a). Even excluding the barn swallow Hirundo rustica, because this bird species responded much more strongly than predicted (see Fig. 1a), we found a significant positive correlation between the number of individuals responding to live cuckoos and the number of individuals responding to dummy cuckoos (Table 1; Fig. 1b). The relative abundance of each bird species and the 
Table 1 Species noted to react to a live cuckoo in the field and to a dummy during dummy presentation experiments

\begin{tabular}{|c|c|c|}
\hline Species & Live cuckoo & Dummy \\
\hline Acrocephalus palustris & 2 & 2 \\
\hline Acrocephalus schoebaneus & 1 & 1 \\
\hline Alauda arvensis & 1 & 0 \\
\hline Anthus pratensis & 1 & 1 \\
\hline Apus apus & 1 & 0 \\
\hline Carduelis carduelis & 1 & 0 \\
\hline Chloris chloris & 1 & 0 \\
\hline Corvus cornix & 3 & 1 \\
\hline Cyanistes cyaneus & 2 & 3 \\
\hline Delichon urbicum & 3 & 4 \\
\hline Emberiza citrinella & 3 & 3 \\
\hline Erithacus rubecula & 2 & 1 \\
\hline Fringilla coelebs & 2 & 0 \\
\hline Hippolais icterina & 1 & 0 \\
\hline Hirundo rustica & 15 & 50 \\
\hline Lanius collurio & 4 & 2 \\
\hline Lanius excubitor & 1 & 0 \\
\hline Motacilla alba & 6 & 2 \\
\hline Motacilla flava & 4 & 1 \\
\hline Muscicapa striata & 1 & 1 \\
\hline Oriolus oriolus & 3 & 0 \\
\hline Parus major & 5 & 9 \\
\hline Passer domesticus & 2 & 1 \\
\hline Passer montanus & 1 & 1 \\
\hline Phoenicurus ochruros & 1 & 0 \\
\hline Phylloscopus collybita & 1 & 2 \\
\hline Phylloscopus trochilus & 1 & 1 \\
\hline Pica pica & 3 & 0 \\
\hline Picus viridis & 1 & 0 \\
\hline Riparia riparia & 1 & 1 \\
\hline Serinus serinus & 1 & 0 \\
\hline Sturnus vulgaris & 4 & 1 \\
\hline Sylvia atricapilla & 2 & 2 \\
\hline Sylvia communis & 1 & 1 \\
\hline Sylvia curruca & 1 & 1 \\
\hline Sylvia nisoria & 1 & 0 \\
\hline Turdus merula & 1 & 0 \\
\hline Turdus pilaris & 3 & 0 \\
\hline Uрирра еррорs & 1 & 0 \\
\hline Total & 89 & 92 \\
\hline
\end{tabular}

interaction with the number of attacks were not significantly related to the response (Table 2).

However, if the number of cases of brood parasitism for each species in Poland was controlled statistically, the correlation between the number of individuals responding to live cuckoos and the number of individuals responding to dummy cuckoos was even more strongly positive and highly significant (partial correlation: $r_{\mathrm{p}}=0.791, d f=38$, $P=0.001$ ).

\section{Discussion}

Although data were obtained in not experimentally controlled conditions, focused mainly on cuckoo males and hence may have some limitations, we found interesting results well worth discussion. We also note that data were collected during the entire breeding season, and we did not search for nests, so we had no information on the nesting stages when the potential hosts mobbed live or stuffed cuckoos. Hosts may show similarly high levels of aggression toward the cuckoo from laying to the nestling period, although that has not been fully confirmed (Moskát 2005). However, the bias applied to both methods, dummies and natural cuckoos. Firstly, we found a strong positive correlation between the intensity of mobbing in playback experiments and observations in the field of live cuckoos. Moreover, this response was stronger for hosts than for non-hosts. However, due to limited sample size, e.g. number of attacks, only one particular case was suitable for analysis, the barn swallow. Liang and Møller (2015) showed that barn swallows reacted as strongly towards dummies as to live cuckoos. Here, we also found that barn swallows mobbed the dummy much more strongly than predicted from field observations of live cuckoos. The barn swallow is known to intensely mob enemies including cuckoos (Møller 1987; Brown and Hoogland 1986; Liang and Møller 2015; Yu et al. 2016). Why are barn swallows so aggressive towards dummies? Liang and Møller (2015) compared attacks on dummies and live cuckoos in China, where the barn swallow is often host of cuckoo. Perhaps the response by barn swallows to dummies is so strong because dummies 'behave' in a way that a live cuckoo would not. Live cuckoos may communicate with hosts, while dummies continue to behave in a way that hosts may consider to be an escalation. Alternatively, barn swallows may consider cuckoos to not only be brood parasites (which is rare in Europe), as documented especially in older studies (Moksnes and Røskaft 2009), but barn swallows may also visually confuse cuckoos with sparrowhawks (Trnka et al. 2012; Gluckman and Mundy 2013; Lyon and Gilbert 2013).

We used a stuffed dummy supplemented with a loudspeaker that played back the call of a cuckoo. This created a different situation from the exclusive use of a silent dummy (Moksnes et al. 1991, 2000; Dyrcz and Hałupka 2006). Therefore, bird responses to live cuckoos did not depend on whether the cuckoo flew or sat, if the key element was the call. Similar reactions to dummies were also reported in studies of predation (e.g. Cockrem and Silverin 2002), and 


\section{a All species}

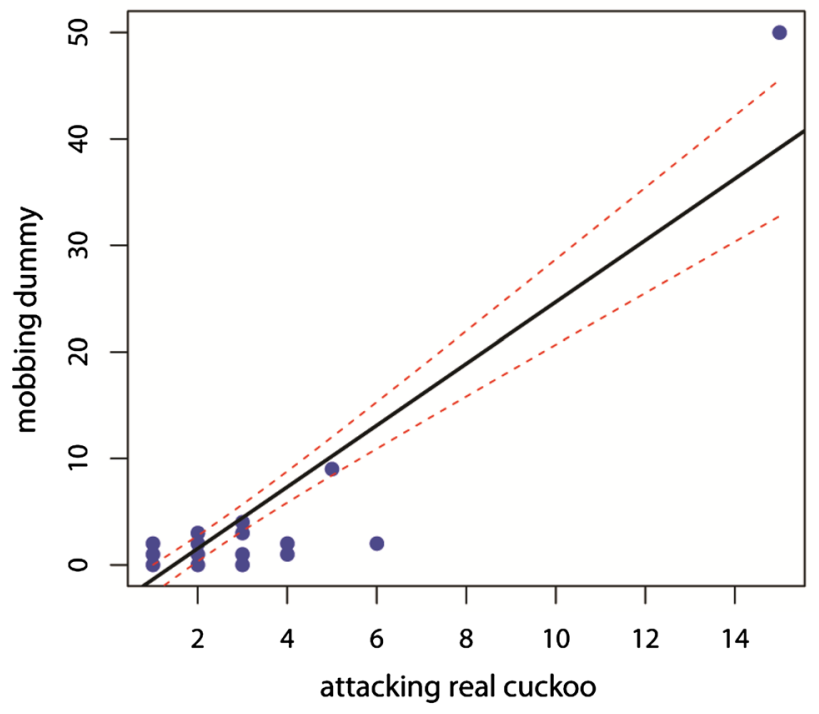

Fig. 1 Correlation between number of bird individuals of each species that attacked a cuckoo ( $x$-axis) in the field and in experimental trials during presentation of a dummy ( $y$-axis) for all species com-

Table 2 Generalized linear model, accounting for association between number of individuals involved in attacks on dummy and number of individuals attacking live cuckoos and the relative abundance of each bird species in the same study area

\begin{tabular}{lrllll}
\hline Predictors & Estimate & CI & SE & $z$ & $P$ \\
\hline Intercept & -0.782 & $-1.644 / 0.017$ & 0.308 & -3.1 & 0.0641 \\
$\begin{array}{l}\text { Attacks on live } \\
\text { cuckoo }\end{array}$ & 0.324 & $0.172 / 0.642$ & 0.119 & 3.4 & 0.0006 \\
$\begin{array}{l}\text { Bird species abun- } \\
\text { dance }\end{array}$ & -0.329 & $-0.678 / 0.259$ & 0.237 & -0.6 & 0.5709 \\
$\begin{array}{l}\text { Attacks on live } \\
\text { cuckoo } \times \text { bird } \\
\text { species abun- } \\
\text { dance }\end{array}$ & 0.023 & $-0.074 / 0.167$ & 0.061 & 0.5 & 0.6346 \\
\hline
\end{tabular}

The table shows standardised estimates, 95\% confidence intervals (CI), SE, $z$ and $P$

this was already suggested for the study of cuckoos (Grim 2005).

Another possibility rather than using both a dummy and a loudspeaker with cuckoo calls is to use more advanced technology, such as mobile models which can produce calls interactively (e.g. Ręk and Magrath 2016). Recently, even 'robo-raptor' models have been used as a powerful tool for providing increased realism in simulated predator encounters without sacrificing experimental control (Carlson et al. 2017). Such models have so far never been used with cuckoos.

In summary, the use of stuffed cuckoo dummies combined with calls caused responses by birds similar to those b All species excluding $\mathrm{H}$. rustica

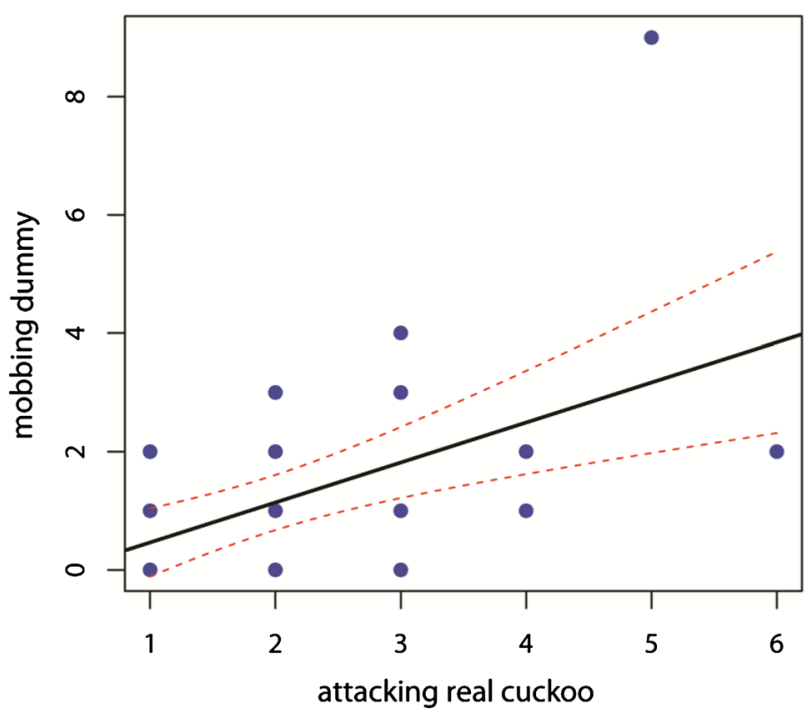

bined (a), and when the barn swallow Hirundo rustica was excluded (b). The lines are the linear regression lines and the 95\% confidence intervals

produced in response to live cuckoos. Cuckoos are recognised by other bird species, and hence the present study confirms the value of using this simple, but efficient and reliable study method (Grim 2005; Liang and Møller 2015).

Acknowledgements We thank Tomasz S. Osiejuk for help with preparing the material for playback experiments, Csaba Moskát and an anonymous referee for valuable comments for the previous version of the manuscript. Our research did not require approval by the Local Ethical Commission because the playback experiments do not fall within its authority in Poland according to The Act on Experiments on Animals (Disposition no. 289 from 2005). The playback was kept as short as possible to collect data for the purposes of the current study and we are unaware of any consequences for breeding or welfare of the subjects.

\section{Compliance with ethical standards}

Conflict of interest The authors declare that they have no conflict of interest.

Open Access This article is distributed under the terms of the Creative Commons Attribution 4.0 International License (http://creativeco mmons.org/licenses/by/4.0/), which permits unrestricted use, distribution, and reproduction in any medium, provided you give appropriate credit to the original author(s) and the source, provide a link to the Creative Commons license, and indicate if changes were made.

\section{References}

Altmann SA (1956) Avian mobbing behavior and predator recognition. Condor 58:241-253. https://doi.org/10.2307/1364703 
Bates D, Maechler M, Bolker B, Walker S (2014) lme4: linear mixedeffects models using Eigen and S4-R Package

Beránková J, Veselý P, Sýkorová J, Fuchs R (2014) The role of key features in predator recognition by untrained birds. Anim Cogn 17:963-971. https://doi.org/10.1007/s10071-014-0728-1

Blondel J, Ferry C, Frochot B (1970) La méthode des indices ponctuels d'abondance (IPA) ou des relevés d'avifaune par "stations d'écoute". Alauda 38:55-71

Brown CR, Hoogland JL (1986) Risk in mobbing for solitary and colonial swallows. Anim Behav 34:1319-1323. https://doi. org/10.1016/S0003-3472(86)80203-2

Carlson NV, Pargeter HM, Templeton CN (2017) Sparrowhawk movement, calling, and presence of dead conspecifics differentially impact blue tit (Cyanistes caeruleus) vocal and behavioral mobbing responses. Behav Ecol Sociobiol 71:133. https://doi. org/10.1007/s00265-017-2361-x

Cockrem JF, Silverin B (2002) Sight of a predator can stimulate a corticosterone response in the great tit (Parus major). Gen Comp Endocrinol 125:248-255. https://doi.org/10.1006/gcen.2001.7749

Courter JR, Ritchison G (2010) Alarm calls of tufted titmice convey information about predator size and threat. Behav Ecol 21:936942. https://doi.org/10.1093/beheco/arq086

Curio E, Ernst U, Vieth W (1978) The adaptive significance of avian mobbing. Zeit Tierpsychol 48:184-202. https://doi. org/10.1111/j.1439-0310.1978.tb00254.x

Dyrcz A, Hałupka L (2006) Great reed warbler Acrocephalus arundinaceus and reed warbler Acrocephalus scirpaceus respond differently to cuckoo dummy at the nest. J Orn 147:649-652. https:// doi.org/10.1007/s10336-006-0097-x

Fletcher TD (2015) QuantPsyc-quantitative psychology tools R package

Gluckman TL, Mundy NI (2013) Cuckoos in raptors' clothing: barred plumage illuminates a fundamental principle of Batesian mimicry. Anim Behav. 86:1165-1181. https://doi.org/10.1016/j.anbeh av.2013.09.020

Grim T (2005) Host recognition of brood parasites: implications for methodology in studies of enemy recognition. Auk 122:530-543. https://doi.org/10.1642/00048038(2005)122[0530:hrobpi]2.0.co;2

Jung WJ, Lee JW, Yoo JC (2014) "Cu-coo": can you recognize my stepparents? A study of host-specific male call divergence in the common cuckoo. PLoS One 9:e90468. https://doi.org/10.1371/ journal.pone.0090468

Knight RL, Temple SA (1986) Methodological problems in studies of avian nest defence. Anim Behav 34:561-566. https://doi. org/10.1016/S0003-3472(86)80125-7

Liang W, Møller AP (2015) Hawk mimicry in cuckoos and anti-parasitic aggressive behavior of barn swallows in Denmark and China. J Avian Biol 46:216-223. https://doi.org/10.1111/jav.00515

Lovászi P, Moskát C (2004) Break-down of arms race between the red-backed shrike (Lanius collurio) and common cuckoo (Cuculus canorus). Behaviour 141:245-262

Lyon BE, Gilbert GS (2013) Rarely parasitized and unparasitized species mob and alarm call to cuckoos. Wilson J Orn 125:627-630. https://doi.org/10.1676/12-162.1

Mclean IG (1987) Response to a dangerous enemy: should a brood parasite be mobbed? Ethology 75:235-245. https://doi. org/10.1111/j.1439-0310.1987.tb00656.x

Melzack R, Penick E, Beckett A (1959) The problem of "innate fear" of the hawk shape: an experimental study with mallard ducks. J Comp Physiol Psychol 52:694-698. https://doi.org/10.1037/ h0038532

Moksnes A, Røskaft E (2009) Egg-morphs and host preference in the common cuckoo (Cuculus canorus): an analysis of cuckoo and host eggs from European museum collections. J Zool 236:625648. https://doi.org/10.1111/j.1469-7998.1995.tb02736.x
Moksnes A, Røskaft E, Braa AT, Korsnes L, Lampe HM, Pedersen HC (1991) Behavioural responses of potential hosts towards artificial cuckoo eggs and dummies. Behaviour 116:64-89. https:// doi.org/10.1163/156853990X00365

Moksnes A, Røskaft E, Hagen LG, Honza M, Mørk C, Olsen PH (2000) Common cuckoo Cuculus canorus and host behaviour at reed warbler Acrocephalus scirpaceus nests. Ibis 142:247-258. https://doi.org/10.1111/j.1474-919X.2000.tb04864.X

Møller AP (1987) Advantages and disadvantages of coloniality in the swallow, Hirundo rustica. Anim Behav 35:819-832. https://doi. org/10.1016/S0003-3472(87)80118-5

Møller AP, Morelli F, Mousseau TA, Tryjanowski P (2016) The number of syllables in Chernobyl cuckoo calls reliably indicate habitat, soil and radiation levels. Ecol Indic 66:592-597. https://doi. org/10.1016/j.ecolind.2016.02.037

Moskát C (2005) Nest defence and egg rejection in great reed warblers over the breeding cycle: are they synchronised with the risk of brood parasitism? Ann Zool Fennici 42:579-586

Moskát C, Elek Z, Bán M, Geltsch N, Hauber ME (2017) Can common cuckoos discriminate between neighbours and strangers by their calls? Anim Behav 126:253-260. https://doi.org/10.1016/j. anbehav.2017.02.013

R Development Core Team (2017) R: a language and environment for statistical computing. R Foundation for Statistical Computing

Ręk P, Magrath R (2016) Multimodal duetting in magpie-larks: how do vocal and visual components contribute to a cooperative signal's function? Anim Behav. 117:35-42. https://doi.org/10.1016/j. anbehav.2016.04.024

Røskaft E, Moksnes A, Stokke BG, Bicík V, Moskát C (2002) Aggression to dummy cuckoos by potential European cuckoo hosts. Behaviour 139:613-628. https://doi.org/10.1163/1568539026 0136735

Schleidt W, Shalter MD, Moura-Neto H (2011) The hawk/goose story: the classical ethological experiments of Lorenz and Tinbergen, revisited. J Comp Psychol 125:121-133. https://doi.org/10.1037/ a0022068

Scriba M, Goymann W (2008) The decoy matters! Hormonal and behavioural differences in the reaction of territorial European robins towards stuffed and live decoys. Gen Comp Endocrinol 155:511-516. https://doi.org/10.1016/j.ygcen.2007.08.001

Soard CM, Ritchison G (2009) 'Chick-a-dee'calls of Carolina chickadees convey information about degree of threat posed by avian predators. Anim Behav 78:1447-1453. https://doi.org/10.1016/j. anbehav.2009.09.026

Specht R (2016) Pro version 5.2. Sound Analysis and Synthesis Laboratory for Microsoft Windows XP/Vista/7/8/8.1/10. Avisoft Bioacoustics, Berlin

Suzuki TN, Ueda K (2013) Mobbing calls of Japanese tits signal predator type: field observations of natural predator encounters. Wilson J Orn 125:412-415. https://doi.org/10.2307/41933207

Syrová M, Němec M, Veselý P, Landová E, Fuchs R (2016) Facing a clever predator demands clever responses: red-backed shrikes (Lanius collurio) vs. Eurasian magpies (Pica pica). PLoS One 11:e0159432. https://doi.org/10.1371/journal.pone.0159432

Teuschl Y, Taborsky B, Taborsky M (1998) How do cuckoos find their hosts? The role of habitat imprinting. Anim Behav 56:1425-1433. https://doi.org/10.1006/anbe.1998.0931

Trnka A, Grim T (2013) Color plumage polymorphism and predator mimicry in brood parasites. Front Zool 10:25. https://doi. org/10.1186/1742-9994-10-25

Trnka A, Prokop P, Grim T (2012) Uncovering dangerous cheats: how do avian hosts recognize adult brood parasites? PLoS One 7:e37445. https://doi.org/10.1371/journal.pone.0037445 
Tryjanowski P, Morelli F (2015) Presence of cuckoo reliably indicates high bird diversity: a case study in a farmland area. Ecol Indic 55:52-58. https://doi.org/10.1016/j.ecolind.2015.03.012

Vogl W, Taborsky B, Taborsky M, Teuschl Y, Honza M (2004) Habitat and space use of European cuckoo females during the egg laying period. Behaviour 141:881-898

Welbergen JA, Davies NB (2008) Reed warblers discriminate cuckoos from sparrowhawks with graded alarm signals that attract mates and neighbours. Anim Behav 76:811-822. https://doi. org/10.1016/j.anbehav.2008.03.020

Welbergen JA, Davies NB (2009) Strategic variation in mobbing as a front line of defense against brood parasitism. Curr Biol 19:235240. https://doi.org/10.1016/j.cub.2008.12.041
Wesołowski T, Mokwa T (2013) Cuckoo's Cuculus canorus hosts and timing of breeding in Poland: analysis of ringing and nest records data. Ornis Pol 54:159-169

Yu J, Wang L, Xing X, Yang C, Ma J, Møller AP, Wang H, Liang W (2016) Barn swallows (Hirundo rustica) differentiate between common cuckoo and sparrowhawk in China: alarm calls convey information on threat. Behav Ecol Sociobiol 70:171-178. https:// doi.org/10.1007/s00265-015-2036-4 